\title{
Prediction of Admission to Delivery Time by Transvaginal Ultrasonographic Assessment of the Cervix in Cases of Preterm Prelabour Rupture of Membranes Omar S. Ayad ${ }^{1}$, Mohammad R. Abd EI Zaher ${ }^{2}$, Mohammad T. Ismaeil ${ }^{2}$ \\ ${ }^{1}$ Department of Obstetrics and Gynecology, Kafr EL-Sheikh General Hospital, ${ }^{2}$ Department of Obstetrics and Gynecology, Faculty of Medicine, Al-Azhar University, Cairo, Egypt \\ Corresponding author: Omar S. Ayad, Email: dr.omar_ayad135@yahoo.com.,Tele: 0201018316781
}

\begin{abstract}
Background: Preterm Premature Rupture of Membranes (PPROM) heralds about 30\% of cases with spontaneous preterm births. Latency in PPROM is delineated as the time interval between PROM and delivery. It might be beneficial to predict this latency period as it may help to make a decision concerning in-utero transfer of fetus to better neonatal centers with advanced facilities and to administer corticosteroids in favor of fetal lung maturity.

Objective: The aim of the current study was to assess the usefulness of measuring the cervical parameters by transvaginal sonography mainly cervical length and posterior cervical angle, in predicting the interval from admission to delivery in women with (PPROM). Subjects and methods: This study was conducted at Kafr El- Shiekh General Hospital and Al-Azhar University Hospitals and included 100 pregnant women with a singleton pregnancy of gestational age between 28-34 weeks and PPROM presenting within 24 hours and not in labour.
\end{abstract}

Results: showed non-significant differences between the mean of PCA among different groups $(\mathrm{P}>0.05)$. Nevertheless, the results indicated that amniotic fluid index (AFI) increased significantly in patients with latency period >7days group $(\mathrm{P}<0.001)$. Furthermore, the mean Cervical length $(\mathrm{CL})$ was observed to increase in PPROM patients' group with high latency period. The latency period had significant positive correlation with AFI and cervical length ( $\mathrm{p}<0.05$ ). Also, it had significant negative correlation with birth weight, gestational age at hospitalization, CRP, and TLC, and neonatal sepsis $(\mathrm{p}<0.05)$.

Conclusion: It could be concluded that assessment of Cervical length via transvaginal sonography is a valuable tool in the evaluating the interval between rupture of membranes and delivery in women with PPROM.

Keywords: PPROM, TVS, Cervical length, posterior cervical angle, latency period.

\section{INTRODUCTION}

Preterm Prelabour rupture of membranes (PPROM) is delineated as fetal membranes rupture prior to 37 weeks of gestation. It has an incidence of 2.7-7\% in China and 5-15\% in America. Moreover, it precedes $30 \%$ of cases with spontaneous preterm births ${ }^{(1)}$. Statistics propose that PPROM birth costs are eight folds more than that of uncomplicated births (2). Serious sequels of PPROM include Chorioamnionitis, postpartum infection, and maternal mortality owing to sepsis. Furthermore, placental abruption is frequent in PPROM cases especially if infection is present. As regard neonatal complications, most of them are allied to prematurity, including respiratory distress syndrome (RDS), hazards of oligohydraminos, sepsis, intraventricular hemorrhage (IVH), necrotizing enterocolitis (NEC), cerebral palsy (CP), and perinatal death. Also, behavioral and educational problems may persist to the school age and adulthood for those who survive ${ }^{(2)}$.

Clinical consequences and management of PPROM remains an area of controversy ${ }^{(3)}$. Digital vaginal examination should be evaded as it upsurges the infection risk and reduce the latency period of entering into labour ${ }^{(4)}$.

Latency in PPROM is outlined as the interval between PROM and delivery ${ }^{(5)}$. It is worth noting that prediction of the time interval between the occurrence of PPROM to delivery may assist for better decision concerning in-utero transfer of neonates to better neonatal centers with advanced neonatal facilities and for administration of corticosteroids for the fetus lung maturation $^{(4)}$.

Transvaginal sonographic imaging of cervix is assumed to be safe. Hence, its use for the prediction of period to delivery in PPROM women may be valuable ${ }^{(5)}$. It is considered the "gold standard" for the diagnosis of a short cervix throughout pregnancy as its accuracy was reported ${ }^{(6)}$. Moreover, cervical length as determined by transvaginal ultrasound has emerged as a powerful means of predicting spontaneous preterm delivery in both women with intact membranes, and in women with PPROM ${ }^{(6)}$. Furthermore, Posterior cervical angle (PCA) which defined as the angle between the posterior uterine wall and cervical canal ${ }^{(8)}$, may reflect more accurate position of the cervix ${ }^{(4)}$.

The aim of the current study was to assess the usefulness of measuring the cervical parameters by transvaginal sonography mainly cervical length and posterior cervical angle, in predicting the interval from admission to delivery in women with (PPROM).

\section{SUBJECTS AND METHODS}

This prospective study included a total of 100 pregnant women, attending at Kafr El-Shiekh General Hospital and Al-Azhar University Hospitals. This study was conducted between February 2018 to December 2018.

Ethical approval:

Approval of the research was taken from quality education assurance unit, Al-Azhar university faculty of medicine, Egypt (approval code: 
Gyn._153

Med.

Research.PPROM.Cervical.Assess.TVUS._000001

53).Each individual participated in the present study was fully informed concerning the nature of the disease and the diagnostic procedures.Informed consent: Informed verebal consent was obtained from all participants included in the study.

\section{Inclusion Criteria:}

The included subjects matched the following three criteria: 1) A singleton pregnancy of gestational age between 28-34 weeks. (2) PPROM clinically confirmed by visualization of amniotic fluid through the cervical os during sterile speculum examination. (3) And presenting within 24 hours of PPROM and not in labour.

\section{Exclusion Criteria:}

Pregnant ladies who were before $28^{\text {th }}$ or after $34^{\text {th }}$ week of gestation, with vaginal bleeding, with fetal heart rate abnormalities, with clinical or biochemical evidence of chorioamnionitis, with cervical cerclage , in labour at admission, or with history of cervical surgery as conization or trachelectomy were excluded from the study.

Complete history taking and physical examination were done at admission. Local examination and sterile speculum examination to confirm PPROM with no digital vaginal examination was performed. Then, all cases were subjected to Routine laboratory investigations including complete blood count (CBC), blood grouping, Rh typing, Creactive protein $(\mathrm{CRP})$ and urine analysis. $\mathrm{BMI}$ was calculated.

\section{Ultrasound Examination:}

All cases underwent: Transabdominal ultrasound examination at admission for assessment of: Fetal viability, number, fetal biometry [biparietal diameter (BPD) - fetal length (FL) - abdominal circumference (AC)], placental (site and maturity), Liquor (amount described as amniotic fluid index (AFI) and turbidity).
Transvaginal ultrasound examination was used for measuring the cervical length and posterior cervical angle by the same operator. The ultrasound equipment used was (MINDRAY DC-N2, China) using a 3.5- 5-MHz transabdominal probe and 5-9 $\mathrm{MHz}$ transvaginal probe.

\section{Technique of ultrasound examination:}

1) Cervical length (CL) measurement:

Patients were requested to empty their bladder before vaginal sonography. Ultrasound examination of the cervix was performed along with standard techniques in the dorsal lithotomy position; a transvaginal probe was inserted in the anterior fornix. The cervical canal was equidistant from the anterior to posterior cervical walls. A sagittal view of the cervix was attained, for visualization of the total cervical canal calipers were used to estimate the distance between the triangular area at the external os and the $\mathrm{V}$-shaped notch at the internal os. The images of cervical length measurements were shown in Figure 1. No fundal pressure was done to avoid contraction the womb. Three measurements were taken, and the shortest one was noted down.

2) Posterior cervical angle (PCA) measurement:

PCA was estimated with a protractor applied to the hard copy images taken in the sagittal plane, at the internal OS level. It was the angle between an imagined track across the cervical canal and the tangential to the posterior uterine wall at its intersection with the internal os. In cases of an excessively curved cervix, the angle was determined at the junction between the line of the cervical length and the posterior uterine wall (figure 1).

Then, all women were admitted at the hospital, managed expectantly in the absence of signs of chorioamnionitis, restricted to bed rest and received antenatal corticosteroids (Dexamethasone 6mg twice daily for 48 hours) and antibiotics (Amoxicillin/ Sulbactam "Unictam" 3 gram per day in two divided doses intravenously for 48 hours). Subsequently it was changed to oral therapy in form of Erythromycin $250 \mathrm{mg}$, four times daily for 10 days and counseled to stay in the hospital until delivery. 


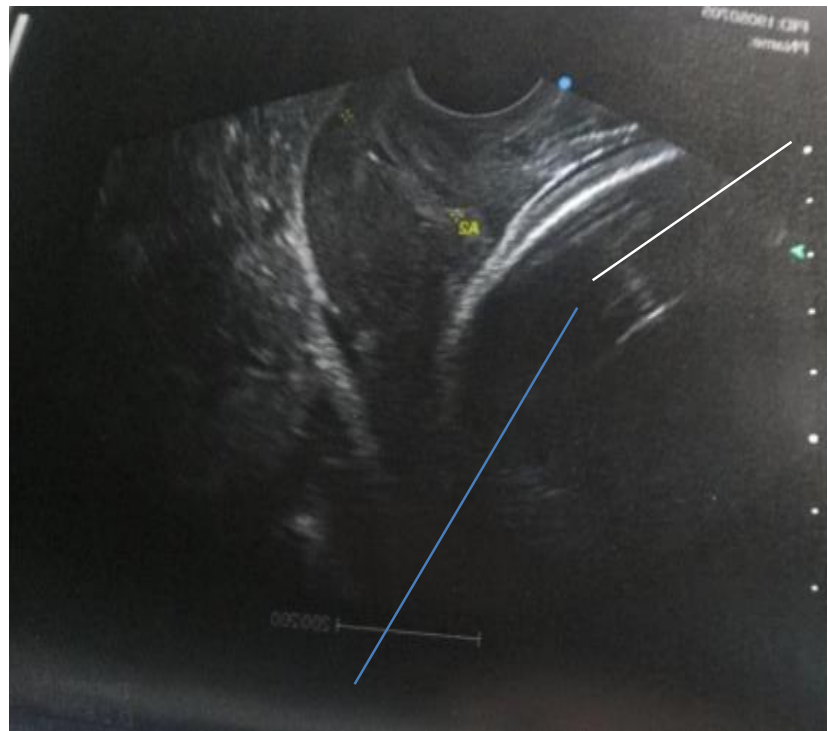

Figure 1: Transvaginal ultrasound of the cervix showing cervical length and posterior cervical angle.

Latency periods between PROM at admission and delivery were recorded to be correlated with demographic, clinical and investigational data and ultrasonographic results of CL and PCA at admission.

In the present study, statistical analyses of data were carried out using SPSS version 23.

\section{RESULTS}

PPROM patients' were divided into 3 groups according to latency period which was calculated from PPROM to delivery; (latency period <2 days, latency period 2-7 days, and latency period $>7$ days). The means of age were $25.57 \pm 3.64,24.95 \pm 2.75$ and 25.14 \pm 3.56 years and the means of BMI were $27 \pm 4.65$,
$27.13 \pm 4.77$ and $25.7 \pm 4.85 \mathrm{~kg} / \mathrm{m}^{2}$ for patients with latency period $<2$ days, latency period 2-7 days and latency period $>7$ days group, respectively (Table 1).

The ANOVA test showed non-significant differences between the mean of age and BMI among different groups $(\mathrm{F}=0.259, \mathrm{P}=0.772$ and $\mathrm{F}=0.974$, $\mathrm{P}=0.381$, respectively). In contrast the ANOVA test showed significant differences between the means of gestational age at both admission and delivery as well as the birth weight among different groups $(\mathrm{F}=11.358$, $\mathrm{P}<0.001, \mathrm{~F}=3.154, \mathrm{P}=0.047$ and $\mathrm{F}=6.197, \mathrm{P}=0.003$, respectively), where the means of gestational age at both admission was $31.6 \pm 1.97,32 \pm 1.49$ and $30.38 \pm$ 1.29 weeks, respectively and that at delivery was 31.6 $\pm 1.97,32.55 \pm 1.32$ and $32.05 \pm 1.22$ weeks, respectively as well as the mean birth weight was $2101.1 \pm 383.1,2288.12 \pm 323.8$ and $2030.4 \pm 299.4$ days, respectively in latency period $<2$ days, latency period 2-7 days and latency period > 7 days group (Table 1). Among pregnancies complicated by PPROM, women with a latency period more than 7 days had a lower gestational age at admission than other groups ( $\mathrm{P}=0.005$ and 0.001 ; respectively). The results revealed that there was significantly increased in the mean gestational age at delivery from patients with latency period (2-7 days) to latency period $<2$ days group $(\mathrm{P}=0.049)$. As for birth weight, the weight increased significantly from patients with latency period $<2$ days to those with latency period 2-7 days group $(\mathrm{P}=0.043)$ whereas, there was a significant decrease in birth weight in patients with latency period $>7$ days compared to those with latency period (2-7 days) $(\mathrm{P}>=0.001)$ (Table 1).

Table (1): Age, BMI, gestational age at admission and delivery, and birth weight of patients with PPROM based on latency period $(\mathrm{N}=100)$.

\begin{tabular}{|c|c|c|c|c|}
\hline \multirow{2}{*}{\multicolumn{2}{|c|}{$\begin{array}{l}\text { Grotips } \\
\text { Parameters }\end{array}$}} & \multicolumn{3}{|c|}{ Latency Period (days) } \\
\hline & & \multirow{2}{*}{$\begin{array}{c}\begin{array}{c}<\text { days } \\
(\mathrm{N}=\mathbf{2 3})\end{array} \\
25.57 \pm 3.64\end{array}$} & \multirow{2}{*}{$\begin{array}{l}\begin{array}{l}2-7 \text { days } \\
(\mathrm{N}=\mathbf{4 0})\end{array} \\
24.95 \pm 2.75\end{array}$} & \multirow{2}{*}{$\begin{array}{l}>7 \text { days } \\
(\mathrm{N}=37) \\
25.14 \pm 3.56\end{array}$} \\
\hline Age (years) & Mean \pm SD & & & \\
\hline \multicolumn{2}{|l|}{ P-value } & & NS & NS \\
\hline BMI $\left(\mathrm{Kg} / \mathrm{m}^{2}\right)$ & Mean \pm SD & $27 \pm 4.65$ & $27.13 \pm 4.77$ & $25.7 \pm 4.85$ \\
\hline \multicolumn{2}{|l|}{ P-value } & _- & NS & NS \\
\hline $\begin{array}{l}\text { Gestational age at } \\
\text { hospitalization (weeks) }\end{array}$ & Mean \pm SD & $31.6 \pm 1.97$ & $32 \pm 1.49$ & $30.38 \pm 1.29$ \\
\hline \multirow{2}{*}{\multicolumn{2}{|c|}{ P-value }} & \multirow{2}{*}{ - } & \multirow{2}{*}{ NS } & $\bar{\nabla}<0.005^{2^{* * *}}$ \\
\hline & & & & $\boldsymbol{\nabla}<0.001^{\mathrm{b}^{* * *}}$ \\
\hline Gestational age at delivery (weeks) & Mean \pm SD & $31.6 \pm 1.97$ & $32.55 \pm 1.32$ & $32.05 \pm 1.22$ \\
\hline \multicolumn{2}{|l|}{ P-value } & - & $0.049^{\mathrm{a}^{*}}$ & NS \\
\hline Birth weight (g) & Mean \pm SD & $2101.1 \pm 383.1$ & $2288.12 \pm 323.8$ & $2030.4 \pm 299.4$ \\
\hline \multicolumn{2}{|l|}{ P-value } & - & $\mathbf{\Delta} \mathbf{\Delta} 0.043^{\mathrm{a}^{*}}$ & $\bar{\nabla} 0.001^{\mathrm{b}^{* * * *}}$ \\
\hline
\end{tabular}

- a: significant difference from Latency Period < 2days, b: significant difference from Latency Period 2-7days,

- *: $\mathrm{P} \leq 0.05, * *: \mathrm{P} \leq 0.01, * * *: \mathrm{P} \leq 0.001$. $\Delta$ Increased $\boldsymbol{\nabla}$ decreased, - NS $=$ Non significant

Moreover, The results (Table 2) showed markedly decrease in the mean level of CRP in PPROM patients' groups with high latency period $\mathrm{P}<0.001$, where, the mean levels of CRP in patients with latency period $<2$ days, latency period 2-7 days and latency period $>7$ days group were $62 \pm 29.37,18.8 \pm 17.44$ and $7.44 \pm 4.69, \mathrm{mg} / \mathrm{dl}$ respectively. The results indicated that serum CRP concentration decreased significantly from patients with latency period <2days to patients with latency period $>7$ days group $(\mathrm{P}<0.001)$. 
Table (2): Mean levels of serum CRP and mean TLC among PPROM patients' groups.

\begin{tabular}{|c|c|c|c|c|}
\hline \multirow{2}{*}{\multicolumn{2}{|c|}{$\begin{array}{l}\text { Groups } \\
\text { Parameters }\end{array}$}} & \multicolumn{3}{|c|}{ Latency Period (days) } \\
\hline & & $\begin{array}{l}<2 \text { days } \\
(\mathrm{N}=\mathbf{2 3}) \\
\end{array}$ & $\begin{array}{l}\begin{array}{l}2-7 \text { days } \\
(\mathrm{N}=40)\end{array} \\
\end{array}$ & $\begin{array}{l}>7 \text { days } \\
(\mathrm{N}=37) \\
\end{array}$ \\
\hline CRP (mg/dl) & $\begin{array}{l}\text { Mean } \pm \\
\text { SD }\end{array}$ & $62 \pm 9.37$ & $18.8 \pm 1.44$ & $7.44 \pm 1.69$ \\
\hline \multicolumn{2}{|l|}{ P-value } & - & $\bar{\nabla}<0.001^{\mathrm{a}^{* * * *}}$ & 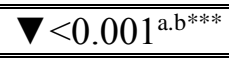 \\
\hline $\operatorname{TLC}\left(10^{3} / \mu \mathrm{L}\right)$ & $\begin{array}{l}\text { Mean } \pm \\
\text { SD }\end{array}$ & $\begin{array}{l}13.449 \pm \\
2.959 \\
\end{array}$ & $10.845 \pm 2.432$ & $9.389 \pm 2.656$ \\
\hline \multirow{2}{*}{\multicolumn{2}{|c|}{ P-value }} & \multirow[t]{2}{*}{ - } & \multirow[t]{2}{*}{$\boldsymbol{\nabla}<0.001^{\mathrm{a}^{* * * *}}$} & $\boldsymbol{\nabla}<0.001^{1^{* * * *}}$ \\
\hline & & & & $\boldsymbol{\nabla}<0.018^{\mathrm{b}^{*}}$ \\
\hline
\end{tabular}

- a : significant difference from Latency Period < 2days, ${ }^{\text {b: }}$ significant difference from Latency Period 2-7days,

- *: $\mathrm{P} \leq 0.05, * *: \mathrm{P} \leq 0.01, * * *: \mathrm{P} \leq 0.001$.

$\Delta$ Increased $\boldsymbol{\nabla}$ decreased, - NS $=$ Non significant

Furthermore, the mean TLC in patients with latency period $<2$ days, latency period 2-7 days and latency period $>7$ days group were $13.449 \pm 2.959$, $10.845 \pm 2.432$ and $9.389 \pm 2.656,\left(10^{3} / \mu \mathrm{L}\right)$ respectively. The ANOVA test showed statistically significant difference in the mean count of total leucocytes among different PPROM groups with $\mathrm{F}=16.755$ and $\mathrm{P}<0.001$.

The ANOVA test showed non-significant differences between the mean of PCA among different groups $(\mathrm{P}>0.05)$.
Nevertheless, the mean levels of AFI in patients with latency period $<2$ days, latency period 27 days and latency period $>7$ days group were $2.36 \pm$ $0.95,2.94 \pm 1.03$ and $4.4 \pm 1.42 \mathrm{~cm}$ respectively. The results indicated that AFI increased significantly in patients with latency period $>7$ days group $(\mathrm{P}<0.001)$. Furthermore, the mean CL was observed to increase in PPROM patients' group with high latency period. The means CL in patients with latency period $<2$ days, latency period 2-7 days and latency period $>7$ days group were $23.35 \pm 3.7,25.3 \pm 3.8$, and $25.73 \pm 2.72$ mm respectively( Table 3 ).

Table (3): Sonographic data for PPROM patients' groups.

\begin{tabular}{|c|c|c|c|c|}
\hline \multirow{2}{*}{\multicolumn{2}{|c|}{$\begin{array}{l}\text { Groups } \\
\text { Parameters }\end{array}$}} & \multicolumn{3}{|c|}{ Latency Period (days) } \\
\hline & & \multirow{2}{*}{$\begin{array}{l}\begin{array}{l}<2 \text { days } \\
(\mathbf{N}=\mathbf{2 3})\end{array} \\
118.522 \pm \\
10.73\end{array}$} & \multirow{2}{*}{$\begin{array}{l}\begin{array}{l}2-7 \text { days } \\
(\mathrm{N}=40)\end{array} \\
117.03 \pm 8.1\end{array}$} & \multirow{2}{*}{$\begin{array}{l}\begin{array}{l}>7 \text { days } \\
(\mathrm{N}=37)\end{array} \\
116.16 \pm 9.92\end{array}$} \\
\hline PCA & $\begin{array}{l}\text { Mean } \pm \\
\text { SD }\end{array}$ & & & \\
\hline \multicolumn{2}{|l|}{ P-value } & 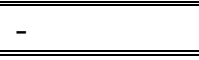 & NS & NS- \\
\hline AFI & $\begin{array}{l}\text { Mean } \pm \\
\text { SD }\end{array}$ & $2.36 \pm 0.95$ & $2.94 \pm 1.03$ & $4.4 \pm 1.42$ \\
\hline \multicolumn{2}{|l|}{ P-value } & - & NS & $\overline{\mathbf{\Delta}}<0.001^{\mathrm{a}, \mathrm{b}^{* * * *}}$ \\
\hline Cervical length (mm) & $\begin{array}{l}\text { Mean } \pm \\
\text { SD }\end{array}$ & $23.35 \pm 3.7$ & $25.3 \pm 3.8$ & $25.73 \pm 2.72$ \\
\hline \multicolumn{2}{|l|}{ P-value } & - & $\mathbf{\Delta} 0.05^{\mathrm{a}^{*}}$ & $\bar{\Delta} \mathbf{\Delta} 0.01^{\mathrm{a}^{* *}}$ \\
\hline
\end{tabular}

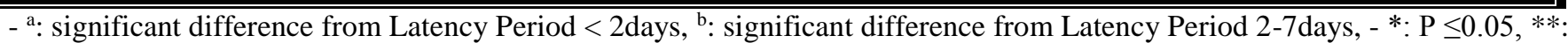
$\mathrm{P} \leq 0.01, * * *: \mathrm{P} \leq 0.001$. $\boldsymbol{\Delta}$ Increased $\boldsymbol{\nabla}$ decreased. - NS $=$ Non significant

In the studied subjects the latency period had significant positive correlation with AFI and cervical length ( $\mathrm{p}<0.05)$. Also, it had significant negative correlation with birth weight, gestational age at hospitalization, CRP, and TLC, and neonatal sepsis $(\mathrm{p}<0.05)$ (figure 2). 

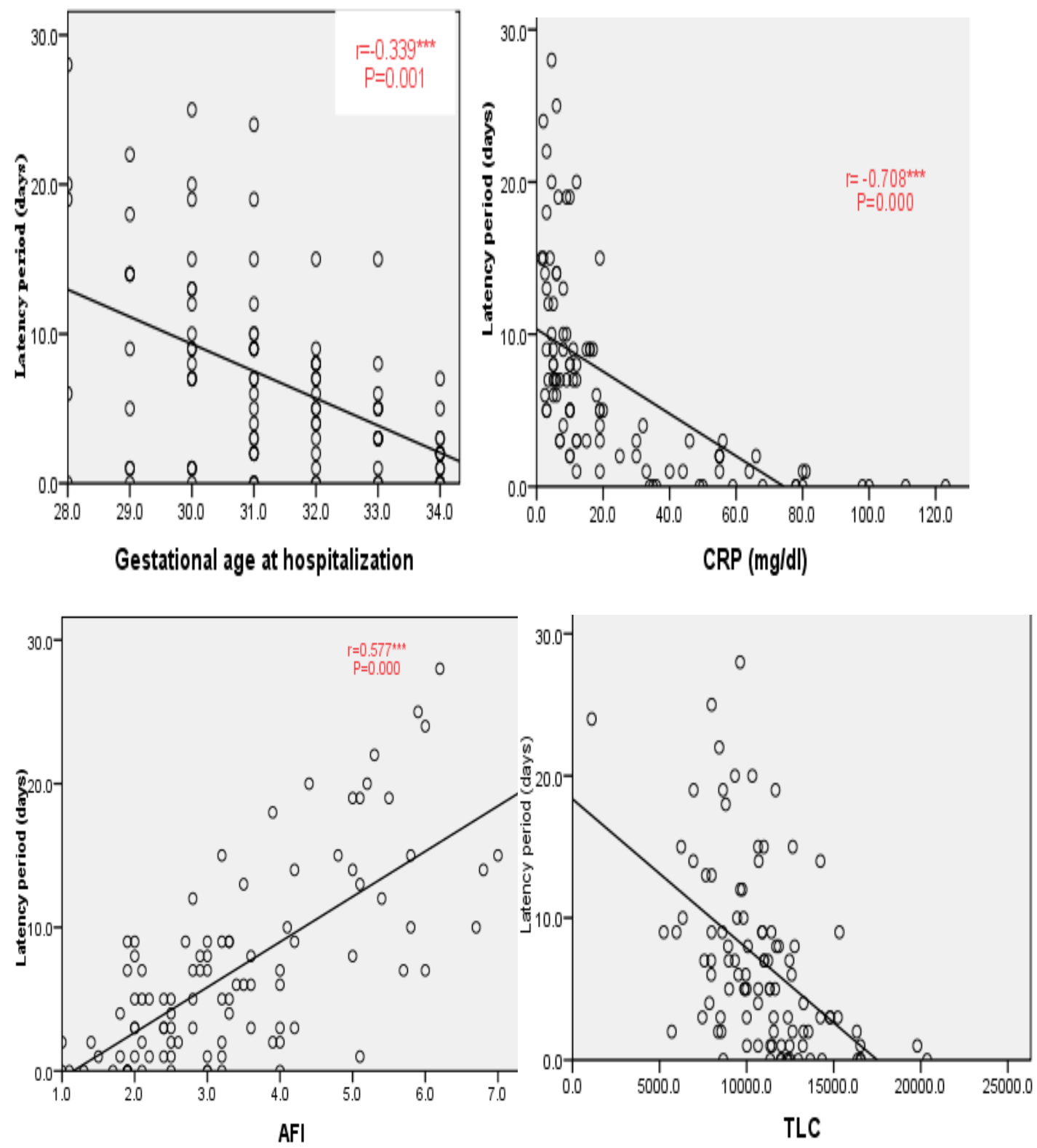

Figure (2): Correlation between latency period, and Other Parameters including Gestational age at hospitalization, CRP, AFI, and TLC.

At last but not least, The ROC curve declared that at a cervical length cutoff value of $23.5 \mathrm{~cm}$ cervical length had a sensitivity, specificity, $52.2 \%, 78.4 \%$ respectively (Figure 3 ).

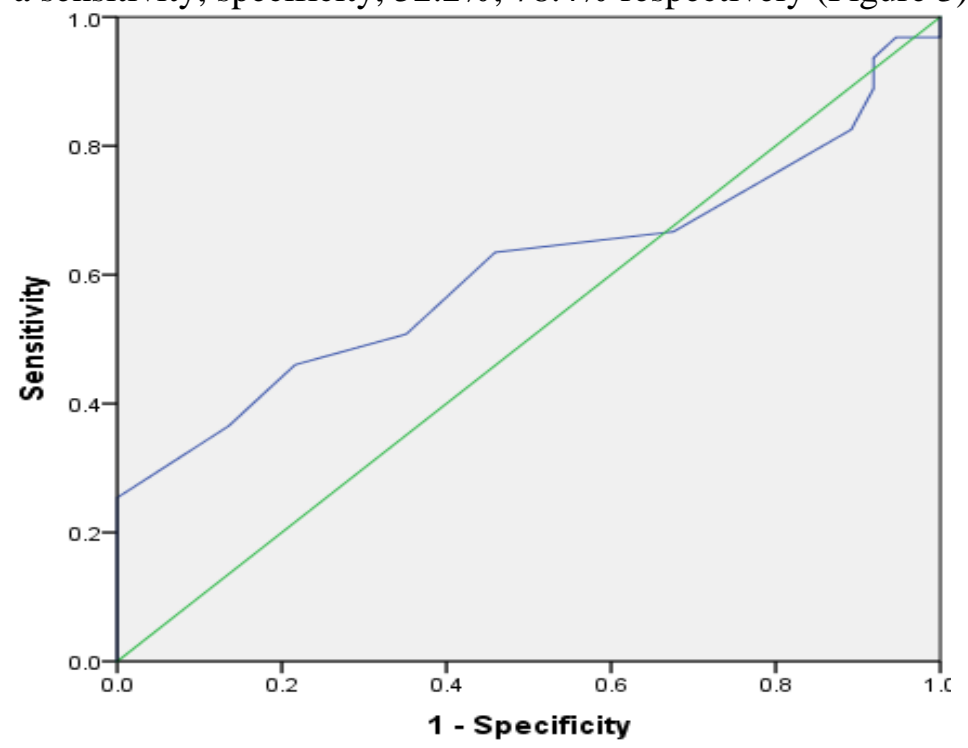

Figure (3): Receiver operating characteristic (ROC) curve of cervical length. 


\section{DISCUSSION}

The competence to expect the usual sequence and duration of the latency period is still limited, and numerous literatures that attempted to clarify the factors affecting it were conducted in the absence of conventional care ${ }^{(9)}$.

Our findings that longer latency period was associated with less neonatal morbidities agreed with Frenette et $\boldsymbol{a l} .{ }^{(10)}$ who mentioned that extended latency periods resulted in decreased prematurityrelated morbidity without a consequent surge in lifethreatening maternal or neonatal infectious morbidity.

Moreover, Nayot et al. ${ }^{(11)}$ who inspected latency stratified by gestational age at PPOMM and examined outcomes at two latency periods: within 72 hours of delivery and beyond 72 hours of delivery. They found that serious and moderate neonatal morbidity incidence was decreased in patients with latency of greater than 72 hours for infants born up to 34 weeks' gestation however, after 34 weeks' gestation, their results did not display any benefit with expectant management.

Current results also have revealed that there was no statistically significant difference between the three groups as regard age and BMI. Similarly, Kathir et al. (4) didn't find any momentous association between latency to delivery and maternal age or parity. Furthermore, Length of latency until delivery appeared to be inversely correlated with the gestational age at which PPROM occurs.

This was in correspondence with Peaceman $\boldsymbol{e t}$ al. ${ }^{(12)}$ research on the interval from time of PPROM to delivery. They observed that median latency between 24-28 weeks was analogous at around 9 days, but it was significantly shorter with PPROM at 29, 30, and 31 weeks $(\mathrm{p}<0.001)$.

In addition, Frenette et al. ${ }^{(10)}$ found that the mainstream of later gestational age women were had latency periods of less than 48 hours, while the majority of women in the earlier gestational age group were associated with latency greater than 48 hours.

Several studies have outlined the fact that in cases with PPROM, the latency period is inversely correlated with gestational age such as, Nayot $\boldsymbol{e t}$ al. ${ }^{\text {(11) }}$ who reported that extension before delivery for $72 \mathrm{~h}$ as a minimum was detected in $67 \%$ of gestations between 25 and 28 weeks, but in only $10 \%$ of pregnancies between 33 and 36 weeks.

Melamed et al. (9) also demonstrated a significant association between early gestation and latency period.

Also, the results of the present work indicated markedly decline in the mean level of CRP in PPROM patients' groups with high latency period $(\mathrm{P}<0.001)$. Furthermore, a marked decrease in the mean total leucocytic count (TLC) was observed in PPROM patients' group with high latency period

However, Çetin et al. ${ }^{(13)}$ found that there was no significant correlation between the mean C-reactive protein (CRP), sedimentation rate, and leukocyte counts at the time of PPROM diagnosis and the latency period in groups.

Musilova et al. ${ }^{(14)}$ stated that maternal WBC count at the admission point in time cannot aid as a non-invasive screening means for identifying complications in PPROM ladies.

As regard sonographic parameters for prediction of length of latency period, TVS of cervical length has professionally served to predict spontaneous preterm delivery in women without PROM in a plenty of former studies ${ }^{(15)}$.

Carlan et al. ${ }^{(15)}$ has confirmed the safety of transvaginal sonography (TVS) without upsurge in peri-partum infection or diminution in latency period compared to those who did not undergo TVS.

The ANOVA test showed non-significant differences between the mean of PCA among different groups $(\mathrm{P}>0.05)$. Nevertheless, the results showed progressively increase in the mean of AFI in PPROM patients' groups with high latency period $(\mathrm{P}<0.001)$. Furthermore, the mean $\mathrm{CL}$ was observed to be increased in PPROM patients' group with high latency period.

Many studies revealed that short cervix was notably concomitant with premature delivery after PPROM $^{(13)}$.

Moreover, our results were in line with a recent study conducted by Mubarak ${ }^{(16)}$, who found a significant difference in AFI which was lesser and a highly significant difference in CL which was shorter in women delivered within 7 days.

Unlikely, Fischer and Austin ${ }^{(17)}$ proclaimed that although cervical length is a crucial prognostic parameter in the preterm labour, it did not correlate with the latency period. However, with subdivision of cervical into two sections with the cut-off of $25 \mathrm{~mm}$, they found significantly shorter latency periods in patients with less than $25 \mathrm{~mm}$.

This can be elucidated as the shorter the cervix, the more the microbial ascent into the lower pole of the uterus, with concurrent release of proinflammatory mediators heading to preterm parturition. Additionally, weakness of the cervix might trigger herniation of the amniotic sac and shortening the barrier and also promoting bacterial ascent and its consequences ${ }^{(\mathbf{1 8})}$.

In contrast, Borna et al. ${ }^{(19)}$ showed that AFI $<5 \mathrm{~cm}$ were not associated with shorter latency until delivery.

Also in contrary to the presenting study, a recent study done by Kathir et al. ${ }^{(4)}$ declared that cervical length at the time of admission following PPROM was not found to be correlated with latency interval. However their outcomes showed that posterior cervical angle assessment using TVS was a beneficial tool in predicting the latency interval in women with PPROM. 
As regard the best cut off value for cervical length it was found that at cutoff of $23.50 \mathrm{~mm}$ the sensitivity was $52.5 \%$ and specificity $78.4 \%$. Between interval delivery $<2$ days and $>2$ days.

Many studies have reported cervical length to be useful in the prediction of latency period and a cut off $2 \mathrm{~cm}$ was found to be associated with shorter interval from membrane rupture to delivery.

Mubarak ${ }^{(16)}$ stated that the validity of CL in predicting labor in women with PPROM when cutoff $=2 \mathrm{~cm}$, with a sensitivity $=52.6 \%$, specificity $=69 \%$, PPV $=60.6 \%$, negative predictive value $(\mathrm{NPV})=$ $61.7 \%$, and accuracy $=61.25 \%$.

\section{CONCLUSION}

It could be concluded that cervical length via transvaginal sonography, amniotic fluid index can be used as predictors of length of latency period in PPROM which need a further research work.

\section{CONFLICT OF INTERESTS}

The authors declare that they have no conflicts of interest.

\section{REFERENCES}

1. Brown RG, Marchesi JR, Lee YS et al. (2018): Vaginal dysbiosis increases risk of preterm fetal membrane rupture, neonatal sepsis and is exacerbated by erythromycin. BioMed Central Medicine, 16: 9-18.

2. Aris IM, Logan S, Lim C et al. (2017): Preterm prelabour rupture of membranes: a retrospective cohort study of association with adverse outcome in subsequent pregnancy. An International Journal of Obstetrics and Gynecology, 124: 1698-1707.

3. Chandra I, Sun L (2017): Third trimester preterm and term premature rupture of membranes: Is there any difference in maternal characteristics and pregnancy outcomes?. Journal of the Chinese Medical Association, 80: 657-661.

4. Kathir V, Maurya D, Keepanasseril A (2017): Transvaginal sonographic assessment of cervix in prediction of admission to delivery interval in preterm premature rupture of membranes. The Journal of MaternalFetal and Neonatal Medicine, 5: 1-4.

5. El-Messidi A, Cameron A (2010): Diagnosis of premature rupture of membranes: inspiration from the past and insights for the future. Journal of Obstetrics and Gynaecology Canada, 32(6): 561-569.

6. Hernandez-Andrade E, Romero R, Ahn $\mathrm{H}$ et al. (2012): Transabdominal evaluation of uterine cervical length during pregnancy fails to identify a substantial number of women with a short cervix. The Journal of Maternal-Fetal and Neonatal Medicine, 25(9): 1682-1689.
7. Lee S, Park K, Jung E et al.(2017): Frequency and clinical significance of short cervix in patients with preterm premature rupture of membranes. PloS one, 12(3), 1-13.

8. Gokturk U, Cavkaytar S, Danısman N (2015): Can measurement of cervical length, fetal head position and posterior cervical angle be an alternative method to Bishop score in the prediction of successful labor induction?. The Journal of Maternal-Fetal and Neonatal Medicine, 28(11): 1360-1365.

9. Melamed N, Hadar E, Ben-Haroush A et al. (2009): Factors affecting the duration of the latency period in preterm premature rupture of membranes. The Journal of Maternal-Fetal and Neonatal Medicine, 22(11): 10511056.

10. Frenette P, Dodds L, Armson BA et al. (2013): Preterm prelabour rupture of membranes: effect of latency on neonatal and maternal outcomes. Journal of Obstetrics and Gynaecology Canada, 35(8): 710-717.

11. Nayot D, Penava D, Da Silva O et al. (2012): Neonatal outcomes are associated with latency after preterm premature rupture of membranes. Journal of Perinatology, 32(12): 970-977.

12.Peaceman AM, Yinglei LA, Rouse DJ et al. (2015): Length of latency with preterm premature rupture of membranes before 32 weeks' gestation. American journal of perinatology, 32(1): 57-62.

13. Çetin C, Büyükkurt S, Cömert E et al. (2015): Predictive factors for latency period in viable pregnancies complicated by preterm premature rupture of the membranes. Turkish Journal of Obstetrics and Gynecology, 12(1): 30-33.

14. Musilova I, Pliskova L, Gerychova $R$ et al. (2017): Maternal white blood cell count cannot identify the presence of microbial invasion of the amniotic cavity or intra-amniotic inflammation in women with preterm prelabor rupture of membranes. PloS one, 12(12): 189-94.

15. Carlan SJ, Richmond LB, O'brien W F (1997): Randomized trial of endovaginal ultrasound in preterm premature rupture of membranes. Obstetrics and Gynecology, 89(3): 458-461.

16. Mubarak AM (2018): Transvaginal cervical length and amniotic fluid index: Can it predict delivery latency following preterm premature rupture of membrane? Medical Journal of Babylon, 15(1): 78-82.

17.Fischer RL, Austin JD (2008): Cervical length measurement by translabial sonography in women with preterm premature rupture of membranes: can it be used to predict the latency period or peripartum maternal infection?. The Journal of Maternal-Fetal and Neonatal Medicine, 21(2): 105-109.

18. Nott JP, Bonney EA, Pickering JD et al. (2016): The structure and function of the cervix during pregnancy. Translational Research in Anatomy, 2: 1-7.

19. Borna S, Borna H, Hantoushzadeh S (2004): 'Perinatal outcome in preterm premature rupture of membranes with Amniotic fluid index $<5(\mathrm{AFI}<5)$. BMC pregnancy and childbirth, 4(1): 15 . 